Original article

\title{
MOLECULAR AND PHYLOGENETIC CHARACTERISATION OF FASCIOLA SPP. ISOLATED FROM CATTLE AND SHEEP IN SOUTHEASTERN IRAN
}

\author{
H. MIRAHMADI ${ }^{1,2}$, P. BIGLERI ${ }^{1,2}$, S. SEKANDARPOUR ${ }^{1,2}$, \\ M. J. MODREK ${ }^{1,2} \&$ R. SHAFIEI ${ }^{3}$ \\ ${ }^{1}$ Infectious Disease and Tropical Medicine Research Center, Zahedan University of \\ Medical Sciences, Zahedan, Iran; ${ }^{2}$ Department of Parasitology and Mycology, \\ Faculty of Medicine, Zahedan University of Medical Sciences, Zahedan, Iran; \\ ${ }^{3}$ Vector-borne Diseases Research Center, North Khorasan University of Medical \\ Sciences, Bojnurd, Iran
}

\begin{abstract}
Summary
Mirahmadi, H., P. Bigleri, S. Sekandarpour, M. J. Modrek \& R. Shafiei, 2018. Molecular and phylogenetic characterisation of Fasciola spp. isolated from cattle and sheep in southeastern Iran. Bulg. J. Vet. Med., 21, No 1, 86-93.

The objective of this study was to determine the genotype of Fasciola spp. in animal hosts from Zahedan, Sistan and Baluchestan province, southeastern Iran using PCR-RFLP. Overall, 50 and 43 adult Fasciola spp. were isolated from bile ducts of naturally infected cattle and sheep. PCR-RFLP with RsaI restriction enzyme and sequence analysis of the first nuclear ribosomal internal transcribed spacer (ITS 1) region from Fasciola spp. were used to conduct the study. RFLP pattern with RsaI produced 180 and $331 \mathrm{bp}$ fragments in $F$. gigantica and amplicons of $F$. hepatica had a size of 77, 104 and $331 \mathrm{bp}$. Results based on PCR-RFLP analysis were confirmed by sequence analysis of representative ITS 1 amplicons. No hybrid forms were detected in the present study. All sheep were infected with $F$. hepatica while cattle were infected with both species. The results of our study showed that $F$. hepatica and $F$. gigantica isolates were of common H1 and G1 haplotypes.
\end{abstract}

Key words: cattle, Fasciola, Iran, genotype, RFLP-PCR, sheep, Sistan and Baluchestan

\section{INTRODUCTION}

Fasciolosis caused by the digenian liver fluke, Fasciola hepatica and F. gigantica, is a neglected emerging disease causing wellness and economic problems in many countries (Mas-Coma et al., 2005). Food containing infected vegetables is the source of this parasitic infection (Mahami-
Oskouei et al., 2011). Human and animal fasciolosis are a serious concern for public and animal health in Iran (Moghaddam et al., 2004; Ashrafi et al., 2006). Animal fasciolosis is common in pasture animals in most areas of Iran and its prevalence reaches up to $50 \%$ in some provinces es- 
pecially in north of Iran (Moghaddam et al., 2004; Rokni, 2008). During the past 20 years, human diseases were reported in some provinces of Iran and two serious human epidemics have been reported in the northern province of Gilan (Ashrafi et al., 2006; Rokni, 2008).

Different morphological criteria between these two species - due to intermediate form existence in different Asian countries - have made accurate recognition difficult (Ashrafi et al., 2006; Ichikawa \& Itagaki, 2010). Molecular methods based on nuclear ribosomal (rDNA) and mitochondrial (mtDNA) genes are capable to differentiate Fasciola species (Itagaki et al., 2005; Mas-Coma et al., 2009; Shafiei et al., 2014).

The province of Sistan and Baluches$\tan$ is located in the southeast of Iran. Previously, this province has not been known as an important endemic area for fasciolosis. Animal fasciolosis is a serious problem causing reduced production, especially in cattle and sheep (Rokni, 2008). Until now, no data are available about the prevalence of Fasciola spp. in this province. However, variations in phenotype criteria, dissemination, host parasites, genotypes and intermediate forms were reported in Pakistan, in vicinity of the province (Itagaki et al., 1998; Khan et al., 2009). Therefore, it seems necessary to set a goal for recognition, prevention and control of the disease (Rokni et al., 2010). It has been advocated to use PCR-RFLP on rDNA genes for this purpose (Marcilla et al., 2002; Huang et al., 2004; Rokni et al., 2010; Shafiei et al., 2013).

The objective of present study was to examine the utility of region between $18 \mathrm{~S}$ and $28 \mathrm{~S}$, the first internal transcribed spacer (ITS1) of rDNA by PCR-RFLP for molecular identification of Fasciola spp. in Sistan and Baluchestan province, Iran.

\section{MATERIALS AND METHODS}

\section{Study area}

The province of Sistan and Baluchestan is one of the 31 Iranian provinces and is located in the southeastern part of the country, bordering Pakistan and Afghanistan (Fig. 1). The capital is Zahedan and the most prominent climatological phe-

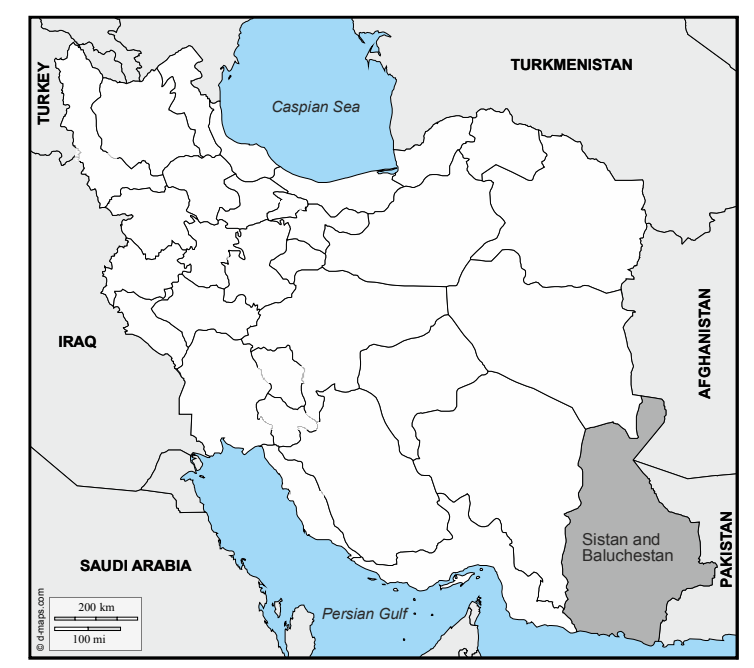

Fig. 1. Map of Sistan and Baluchestan province, Iran. 
nomenon of the region is the heat. Basically the climate of the province is characterised by long, hot and dry summers and short winters, whereas in the coastal region, near the Oman Sea, the weather is warm with a high percentage of humidity. Traditional farming and stock breeding of ruminants provide suitable conditions for transmission of fasciolosis in this area.

\section{Parasite}

A total of 50 and 43 adult Fasciola spp. was isolated from bile ducts of naturally infected cattle and sheep from two slaughterhouses at Zahedan. Individual worms were washed extensively in PBS buffer $\left(37^{\circ} \mathrm{C}\right)$ and subsequently fixed in $70 \%$ ethanol and maintained at room temperature for several weeks until extraction of genomic DNA.

\section{DNA extraction}

Approximately $10 \mathrm{mg}$ tissue was removed from a portion of the lateral zone of adult flukes and then crushed. The ethanol was allowed to evaporate in each of samples for a few minutes and then washed 3 times in distilled water and squashed before the genomic DNA was extracted. Bioneer AccuPrep ${ }^{\circledR}$ kit was used for genomic DNA extraction of Fasciola parasites. The extracted DNA, split into aliquots was stored at $-20{ }^{\circ} \mathrm{C}$ until used in the PCR.

\section{Polymerase chain reaction (PCR)}

To amplify a region of a $700 \mathrm{bp}$ region of ITS1, PCR was performed using F: (5'ACCGGTGCTGAGAAGACG-3') and R: (5'-CGACGTACGTGCAGTCCA-3') primers (Aryaeipour et al., 2014). The total volume of reaction was $30 \mu \mathrm{L}$ containing $3 \mu \mathrm{L}$ DNA template, $15.5 \mu \mathrm{L}$ distilled water, 10 pmol $(1 \mu \mathrm{L})$ of each primers (Forward and Reverse), and 9.5 $\mu \mathrm{L}$ master mix (amplicon). PCR amplification was performed in Eppendorf Mastercycler Gradient thermocycler. The temperature profile was as followed: an initiation of $95{ }^{\circ} \mathrm{C}$ for $5 \mathrm{~min}$, followed by 30 cycles of $94{ }^{\circ} \mathrm{C}$ for $30 \mathrm{~s}$ (denaturation), $60{ }^{\circ} \mathrm{C}$ for $30 \mathrm{~s}$ (annealing), $72{ }^{\circ} \mathrm{C}$ for $30 \mathrm{~s}$ (extension) and a final extension of $72{ }^{\circ} \mathrm{C}$ for $5 \mathrm{~min}$ followed by cooling at $4{ }^{\circ} \mathrm{C}$. The DNA product was sequenced and Fasciola species were identified.

Restriction fragment length polymorphism (RFLP)

After sequencing, using NEBcutter V2.0 software, the cutting sites of commercially available restriction enzymes on ITS1 sequences of $F$. hepatica and $F$. gigantica were assessed (Shafiei et al., 2013). RsaI enzyme (Vivantis) was selected for RFLP method that caused the separation specifically of Fasciola species. To perform RFLP, $10 \mu \mathrm{L}$ of Fasciola ITS1 PCR product, $2 \mu \mathrm{L}$ of supplied restriction enzyme buffer, $2 \mu \mathrm{L}$ of restriction enzyme diluted, and DD. $\mathrm{H}_{2} \mathrm{O}$ up to $30 \mu \mathrm{L}$ were provided. As per manufacturer instruction, the tubes were incubated at $37^{\circ} \mathrm{C}$ for $12 \mathrm{~h}$, to ensure full cutting of fragments. For analysing the digestion products, $15 \mu \mathrm{L}$ of each product in addition to $2 \mu \mathrm{L}$ of loading buffer were run in $2 \%$ gel electrophoresis.

DNA sequencing and phylogenetic analysis

PCR products of ITS1 from eight isolates, six samples from $F$. gigantica from cattle and two samples from $F$. hepatica of each host (cattle, sheep) were purified from the agarose gel, using PCR purification kit (Bioneer, Korea), and sequenced from both directions (Applied Biosystems, DNA Analyzers Sequencing, Bioneer, Korea, Sanger method), using the same primers which were used in the PCR. Multiple alignments were performed with data re- 

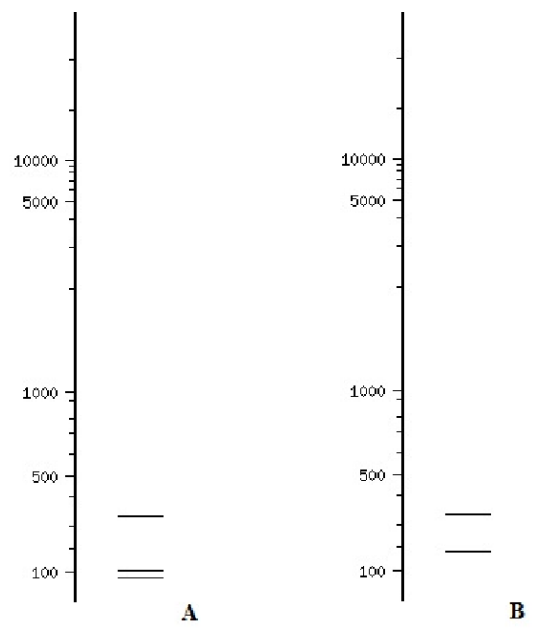

Fig. 2. Cutting sites of RsaI restriction enzyme on A) F. hepatica, B) F. gigantica.

lated to Fasciola spp. from Iran and other countries deposited in Gen-Bank using BioEdit Sequence Alignment Editor Vr. 7.2.5 software. A Neighbor-Joining tree was constructed using the MEGA 5.0 software. Bootstrap analyses (using 1,000 replicates) were carried out to determine the robustness of the finding (Shafiei et al., 2014).

\section{RESULTS}

Genomic DNA from 93 isolates of Fasciola was extracted and eight of them confirmed by sequencing. All amplified products of Fasciola were digested with the RsaI restriction endonuclease and two species were distinguished. The RFLP pattern results showed that out of $50 \mathrm{Fas}$ ciola isolates of cattle, 3 isolates $(6 \%)$ were $F$. hepatica and 47 (94\%) had a pattern corresponding to $F$. gigantica. All 43 isolates $(100 \%)$ from sheep had a RFLP pattern corresponding to $F$. hepatica.

Based on NEBcutter pattern, RsaI which showed effect on GTAC nucleotides in the amplicons of $F$. gigantica had one cutting site and the digested DNA fragments were 180 and $331 \mathrm{bp}$ whereas in the amplicons of $F$. hepatica with two cutting sites, the digested DNA fragments were 77, 104 and 331 bp (Fig. 2). However, the resultant bands of the fragments were about $180 \mathrm{bp}$ in $F$. gigantica and $104 \mathrm{bp}$ in $F$. hepatica (Fig. 3). The other band was not detected on agarose gels.

Complete sequences of $700 \mathrm{bp}$ ITS1 of the flukes were aligned with those of available sequences in GenBank. Ninety-

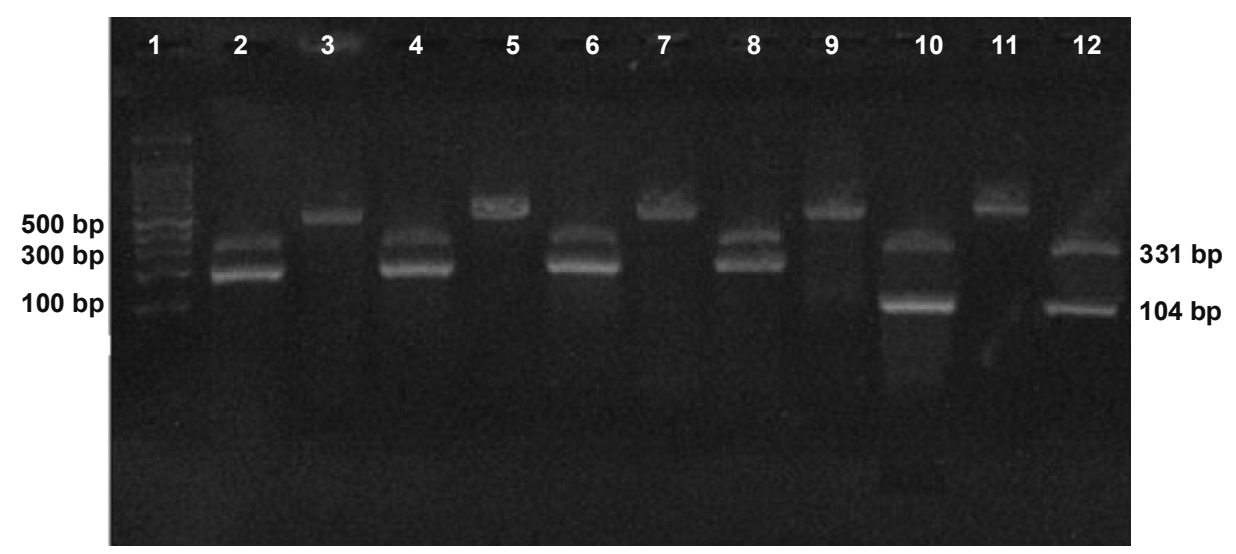

Fig. 3. PCR-RFLP pattern of Fasciola after digestion with RsaI restriction enzyme.

Lane 1: 100 bp DNA ladder; lanes 2, 4, 6, 8: F. gigantica from cattle; lane 10: F. hepatica from sheep; lane 12: F. hepatica from cattle; lanes 3, 5, 7, 9: DNA Fasciola without restriction enzyme. 


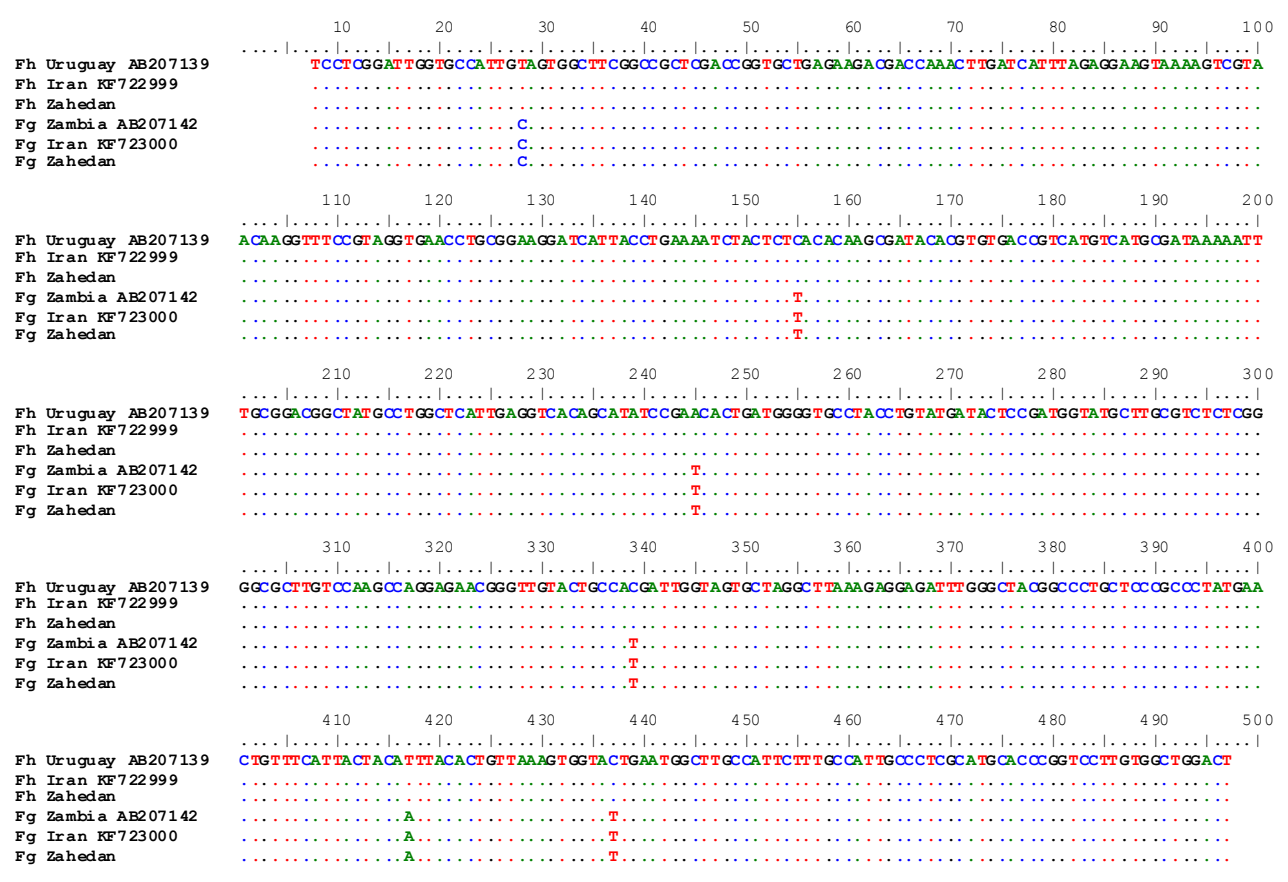

Fig. 4. Alignment of ITS1 sequence of $F$. hepatica (AB207139, KF722999) and $F$. gigantica (AB207142, KF723000), with $F$. gigantica and $F$. hepatica of Sistan and Baluchestan province, Iran

hundred percent similarities were obtained when comparing these sequences with all available data of Fasciola spp. in GenBank. The sequences of $F$. hepatica from cattle and sheep and the sequences between $F$. gigantica had complete similarity. Alignment of the sequences of ITS1 showed six DNA variable sites in which nucleotides at the position of 28, 155, 255, 339, 417 and 437 were single-base substituted resulting in segregation of the specimens into two different groups (genotypes). The main differences between $F$. gigantica and $F$. hepatica were the single-base substitution of $\mathrm{T}>\mathrm{C}$ at nucleotide site of $28, \mathrm{C}>\mathrm{T}$ at the sites of 155,339 , and $437, \mathrm{~A}>\mathrm{T}$ at the site of 255 and $\mathrm{T}>\mathrm{A}$ at the site of 417 (Fig. 4).

The phylogenic tree of ITS 1 showed that flukes were scattered as pure $F$. hepatica and $F$. gigantica clusters, suggest- ing that two genotypes of Fasciola are able to infect animals and probably humans in southestern of Iran (Fig. 5).

\section{DISCUSSION}

DNA analysis is an appropriate plan for understanding the different species of Fasciola and performance of control procedures in an endemic area (Itagaki et al., 2005; Peng et al., 2009; Shafiei et al., 2014). RFLP assay is a major method for detection of two species of Fasciola. In this study we used a reliable, rapid and truthful method based on ITS1-RFLP assay on Fasciola species with RsaI restriction enzyme to show two different patterns for both Fasciola species in Sistan and Balichestan province. Our study did not detect any mixed patterns in this re- 


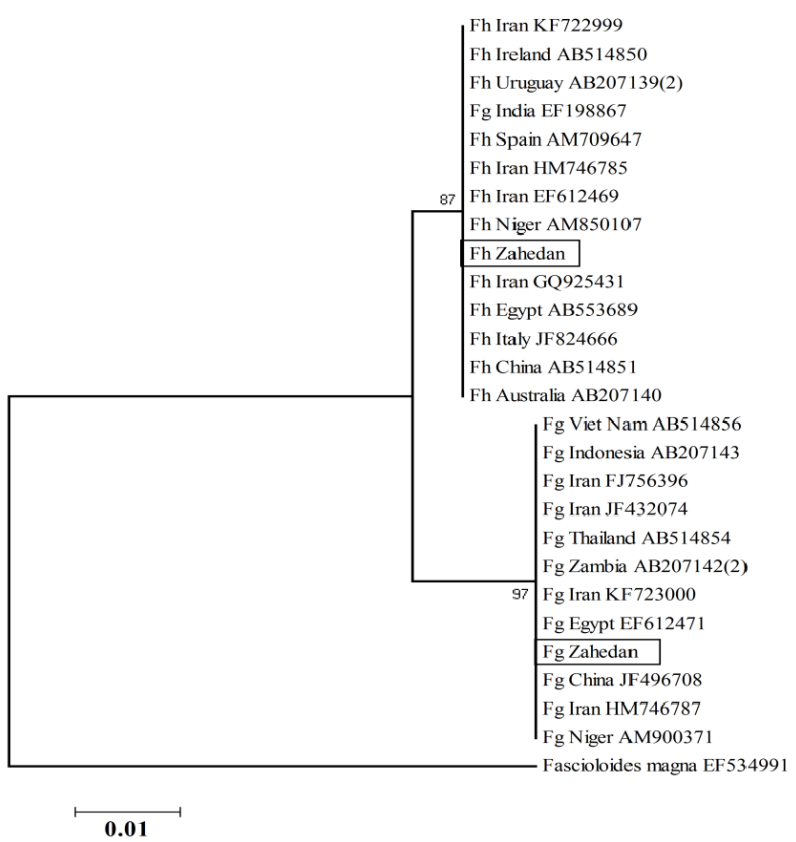

Fig. 5. Phylogenetic relationship of ITS1 sequences of isolates of $F$.hepatica and $F$. gigantica from Iran using Neighbor-Joining method. Fascioloides magna (AN: EF534991) was used as the out group.

gion. The result of our study was similar to that of Ichikawa (2010) which recommended the first RsaI restriction enzyme in ITS1 to specifically distinguish $F$. hepatica from $F$. gigantica (Ichikawa \& Itagaki, 2010).

The RFLP pattern was utilised for accurate differentiation between Fasciola species in different studies in Iran (Karimi, 2008; Saki et al., 2011; Shafiei et al., 2013). Shafiei et al. (2013) used RsaI enzyme in RFLP-PCR method to specifically distinguish $F$. hepatica and $F$. gigantica in ITS1 region. They did not report intermediate form in their study. Aryaeipour et al. (2014) showed that RsaI restriction enzyme was an appropriate enzyme to differentiate both species. The TasI enzyme was used on ITS1 region in RFLP method and differentiation between both species was reported (Rokni et al.,
2010). In another study, Karimi (2008) utilised Bfrl and DraI enzymes in 18S DNA region in RFLP method and showed that BfrI could differentiate two aforementioned parasites while DraI could not differentiate any profile (Karimi, 2008). It was also shown that AvaII and DraII restriction enzymes in 28S DNA are suitable for differentiation between both species (Saki et al., 2011). In a study conducted by Ghavami et al. (2009) BamHI and PagI restriction enzymes on ITS2 gene showed specificity for $F$. hepatica identification and had no effect on $F$. gigantica (Ghavami et al., 2009).

The results of our study were consistent with most of previous studies and demonstrated polymorphism of two species of Fasciola in ITS1 region with six variable nucleotides sites (Itagaki et al., 2005; Peng et al., 2009; Aryaeipour et al., 
Molecular and phylogenetic characterisation of Fasciola spp. isolated from cattle and sheep ....

2014; Shafiei et al., 2014). The phylogenetic tree with high bootstrap showed a close relationship of our isolates with those sequences registered in Genbank from other regions of the world. According to the phylogenetic tree, isolates belonging to $F$. hepatica and $F$. gigantica of our study as mentioned in other regions of Iran were of the common H1 and G1 haplotypes.

\section{ACKNOWLEDGEMENTS}

This study was performed as part of MSc student thesis of Parisa Bigleri, and it was financially supported by the grant No.7213, provided from Zahedan University of Medical Sciences, Zahedan, Iran

\section{REFERENCES}

Aryaeipour, M., S. Rouhani, M. Bandehpour, H. Mirahmadi, B. Kazemi \& M. B. Rokni, 2014. Genotyping and phylogenetic analysis of Fasciola spp. isolated from sheep and cattle using PCR-RFLP in Ardabil province, northwestern Iran. Iranian Journal of Public Health, 43, 1364-1371.

Ashrafi, K., M. A. Valero, M. Panova, M. V. Periago, J. Massoud \& S. Mas-Coma, 2006. Phenotypic analysis of adults of Fasciola hepatica, Fasciola gigantica and intermediate forms from the endemic region of Gilan, Iran. Parasitology International, 55, 249-260.

Ghavami, M. B., P. Rahimi, A. Haniloo \& S. N. Mosavinasab, 2009. Genotypic and phenotypic analysis of Fasciola isolates. Iranian Journal of Parasitology, 4, 61-70.

Huang, W. Y., B. He, C. R. Wang \& X. Q. Zhu, 2004. Characterisation of Fasciola species from Mainland China by ITS-2 ribosomal DNA sequence. Veterinary Parasitology, 120, 75-83.

Ichikawa, M. \& T. Itagaki, 2010. Discrimination of the ITS1 types of Fasciola spp. based on a PCR-RFLP method. Parasitology Research, 106, 757-761.

Itagaki, T., M. Kikawa, K. Sakaguchi, J. Shimo, K. Terasaki, T. Shibahara, K. Fukuda, 2005. Genetic characterization of parthenogenic Fasciola sp. in Japan on the basis of the sequences of ribosomal and mitochondrial DNA. Parasitology, 131, 679-685.

Itagaki, T. \& K. Tsutsumi, 1998. Triploid form of Fasciola in Japan: genetic relationships between Fasciola hepatica and Fasciola gigantica determined by ITS-2 sequence of nuclear rDNA. International Journal for Parasitology, 28, 777-781.

Karimi, A., 2008. Genetic diagnosis of Fasciola species based on $18 \mathrm{~S}$ ribosomal DNA sequences. Journal of Biological Sciences, 8, 1166-1173.

Khan, M. K., M. S. Sajid, M. N. Khan, Z. Iqbal \& M. U. Iqbal, 2009. Bovine fasciolosis: Prevalence, effects of treatment on productivity and cost benefit analysis in five districts of Punjab, Pakistan. Research in Veterinary Science, 87, 70-75.

Mahami-Oskouei, M., A. Dalimi, M. Forouzandeh-Moghadam \& M. B. Rokni, 2011. Molecular identification and differentiation of Fasciola isolates using PCR-RFLP method based on internal transcribed spacer (ITS1, 5.8S rDNA, ITS2). Iranian Journal of Parasitology, 6, 35-42.

Marcilla, A., M. D. Bargues \& S. Mas-Coma, 2002. A PCR-RFLP assay for the distinction between Fasciola hepatica and Fasciola gigantica. Molecular and Cellular Probes, 16, 327-333.

Mas-Coma, S., M. D. Bargues \& M. A. Valero, 2005. Fascioliasis and other plantborne trematode zoonoses. International Journal for Parasitology, 35, 1255-1278.

Mas-Coma, S., M. A. Valero \& M. D. Bargues, 2009. Chapter 2. Fasciola, lymnaeids and human fascioliasis, with a global overview on disease transmission, epidemiology, evolutionary genetics, molecular epidemiology and control. Advances in Parasitology, 69, 41-146. 
Moghaddam, A. S., J. Massoud., M. Mahmoodi., A. H. Mahvi, M. V. Periago, P. Artigas., M. V. Fuentes, M. D. Bargues, S. Mas-Coma, 2004. Human and animal fascioliasis in Mazandaran province, northern Iran. Parasitology Research, 94, 61-69.

Peng, M., M. Ichinomiya, M. Ohtori, M. Ichikawa, T. Shibahara \& T. Itagaki, 2009. Molecular characterization of Fasciola hepatica, Fasciola gigantica, and aspermic Fasciola sp. in China based on nuclear and mitochondrial DNA. Parasitology Research, 105, 809-815.

Rokni, M. B., 2008. The present status of human helminthic diseases in Iran. Annals of Tropical Medicine and Parasitology, 102, 283-295.

Rokni, M. B., H. Mirhendi, A. Mizani, M. Mohebali, M. Sharbatkhori, H. Abdoli \& S. Izadi, 2010. Identification and differentiation of Fasciola hepatica and Fasciola gigantica using a simple PCR-restriction enzyme method. Experimental Parasito$\log y, \mathbf{1 2 4}, 209-213$.

Saki, J., S. Khademvatan \& E. Yousefi, 2001. Molecular identification of animal Fasciola isolates in Southwest of Iran. Australian Journal of Basic and Applied Sciences, 5, 1878-1883.

Shafiei, R., B. Sarkari \& A. Moshfe, 2013. A consistent PCR-RFLP assay based on ITS2 ribosomal DNA for differentiation of Fasciola species. Iranian Journal of Basic Medical Sciences, 16, 1266-1269.
Shafiei, R., B. Sarkari, S. M. Sadjjadi, G. R. Mowlavi \& A. Moshfe, 2014. Molecular and morphological characterization of Fasciola spp. isolated from different host species in a newly emerging focus of human fascioliasis in Iran. Veterinary Medicine International, http://dx.doi.org/ $10.1155 / 2014 / 405740$

Paper received 25.05.2016; accepted for publication 30.09.2016

\section{Correspondence}

Dr. Mohammad Jafari Modrek Infectious Diseases and Tropical Medicine Research Center, Zahedan University of Medical Sciences, Zahedan, Iran, tel: $+98-9155415930$ e-mail: mjmodrek@gmail.com

Dr. Reza Shafiei

Vector-borne Diseases Research Center, North Khorasan University of Medical Sciences,

Bojnurd, Iran, tel:+98-9157029331, e-mail: reza_shafi@yahoo.com 